\title{
Three-dimensional evaluation of the correlation between lip canting and craniofacial planes
}

\author{
Jun-Young Kim ${ }^{\mathrm{a}}$ (1) \\ Hee-Keun Park ${ }^{\mathrm{b}}$ \\ Seung-Woo Shin ${ }^{\mathrm{a}}$ \\ Jin Hoo Park ${ }^{\mathrm{a}}$ \\ Hwi-Dong Jung ${ }^{\mathrm{a}}$ \\ Young-Soo Jung ${ }^{\mathrm{a}}$ (1)
}

${ }^{a}$ Department of Oral and Maxillofacial Surgery, Oral Science Research Center, Yonsei University College of Dentistry, Seoul, Korea

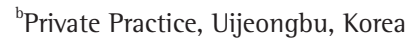

Objective: This study aimed to analyze the correlation of horizontal and sagittal planes used in two-dimensional diagnosis with lip canting by using threedimensional (3D) analysis. Methods: Fifty-two patients (25 men, 27 women; average age: 24 years) undergoing treatment for dentofacial deformity were enrolled. Computed tomography images were acquired, and digital imaging and communication in medicine files were reconstructed into a $3 \mathrm{D}$ virtual model wherein horizontal and sagittal craniofacial planes were measured. Subsequently, the correlations of lip canting with these horizontal and sagittal planes were investigated. Results: The mandibular symmetry plane, the occlusal plane, Camper's plane, the mandibular plane, Broadbent's plane, and the nasal axis plane were correlated with the amount of lip canting (Pearson's correlation coefficients: $0.761,0.648,0.556,0.526,0.438$, and 0.406 , respectively). Planes associated with the lower part of the face showed the strongest correlations; the strength of the correlations decreased in the midfacial and cranial regions. None of the planes showed statistically significant differences between patients with clinical lip canting $\left(>3^{\circ}\right)$ and those without prominent lip canting. Conclusions: The findings of this study suggest that lip canting is strongly correlated with the mandibular symmetry plane, which includes menton deviation. This finding may have clinical implications with regard to the treatment of patients requiring correction of lip canting. Further studies are necessary for evaluating changes in lip canting after orthognathic surgery.

[Korean J Orthod 2020;50(4):258-267]

Key words: Three-dimensional cephalometrics, Three-dimensional diagnosis, Lip canting, Facial asymmetry

Received December 10, 2019; Revised March 10, 2020; Accepted March 27, 2020.

Corresponding author: Young-Soo Jung.

Professor, Department of Oral and Maxillofacial Surgery, Yonsei University College of Dentistry, 50-1 Yonsei-ro, Seodaemun-gu, Seoul 03722, Korea.

Tel +82-2-2228-3139 e-mail ysjoms@yuhs.ac

Jun-Young Kim and Hee-Keun Park contributed equally to this study.

How to cite this article: Kim JY, Park HK, Shin SW, Park JH, Jung HD, Jung YS. Threedimensional evaluation of the correlation between lip canting and craniofacial planes. Korean J Orthod 2020;50:258-267.

(C) 2020 The Korean Association of Orthodontists.

This is an Open Access article distributed under the terms of the Creative Commons Attribution Non-Commercial License (http://creativecommons.org/licenses/by-nc/4.0) which permits unrestricted non-commercial use, distribution, and reproduction in any medium, provided the original work is properly cited. 


\section{INTRODUCTION}

Facial asymmetry is one of the most common conditions for which patients seek treatment in maxillofacial surgery departments, and it can be caused by several factors, including congenital and developmental factors. ${ }^{1}$ Asymmetry related to lip canting, which is observed caudal to the orbital region, nose, dental region, lip, and chin, is more apparent than that related to the cranium or eye. ${ }^{2}$ Asymmetries of the jaw and nose are routinely treated by orthognathic surgery or rhinoplasty, and these surgeries provide predictable outcomes. ${ }^{3}$ However, asymmetry may persist when occlusal plane or lip canting persists. ${ }^{4}$ In many cases of dentofacial deformities requiring orthognathic surgery, the inclination of the lip can be confirmed. Persistence of the lip canting after surgery results in reduced patient satisfaction. Therefore, lip canting and the causative factors should be considered during surgical treatment planning. ${ }^{5}$

Padwa et al. $^{6}$ reported that occlusal canting can be perceived in $90 \%$ of patients if it exceeds $3^{\circ}$. Chu et al. ${ }^{7}$ reported that asymmetry of the oral commissure measuring $<3 \mathrm{~mm}$ and eye canting were not recognized as clinically insignificant. Lip canting is known to play an important role in the attractiveness of the face, ${ }^{8}$ according to Song et al., ${ }^{9} 55.3 \%$ adults without facial deformities exhibit lip canting.

Lip canting is a line connecting both sides of the lip commissure when observed from the front. It is affected by the adjacent hard and soft tissues and caused by a difference in height between the left and right corners. ${ }^{10}$ lip canting is an important parameter in orthodontic treatment because many people are aware of the associated asymmetry and occasionally exhibit residual lip canting after conventional bimaxillary orthognathic surgery. Most studies related to lip canting have been based on the clinical photographs and cephalograms of patients. Although this method is inexpensive ${ }^{11}$ and easy, ${ }^{12}$ inherent limitations of two-dimensional (2D) images result in errors during overlapping of the skeletal

Table 1. Anatomical landmarks used in the present study and their definitions

\begin{tabular}{|c|c|}
\hline Landmark & Definition \\
\hline Anterior nasal spine (ANS) & The most anterior point of the nasal spine \\
\hline Cheilion $(\mathrm{Ch})$ & The most lateral point at the angle of the lips \\
\hline Mid-cheilion (MidCh) & The mid-point of both cheilions \\
\hline Columella (Col) & $\begin{array}{l}\text { The most anterior point of soft tissue columella that links the nasal tip to the nasal } \\
\text { base and separates the nares }\end{array}$ \\
\hline Tragus (Tr) & The lateral center point of the tube running from the outer ear to the middle ear \\
\hline Mid-tragus (MidTr) & The mid-point of both external auricular canal points \\
\hline Genial tubercle (GT) & $\begin{array}{l}\text { The mid-point of prominence on each side of the mental protuberance of the } \\
\text { mandible }\end{array}$ \\
\hline Lens (L) & The mid-point of center of lens on each side \\
\hline Gonion (Go) & $\begin{array}{l}\text { The most outward point on the angle of the mandible formed by the junction of the } \\
\text { ramus and the body of the mandible }\end{array}$ \\
\hline Menton (Me) & The most inferior point of the chin in the sagittal view \\
\hline $\begin{array}{l}\text { Mesiobuccal cusp of upper first molar } \\
\text { (\#16 MBC, \#26 MBC) }\end{array}$ & Mesiobuccal cusp of upper first molar \\
\hline Mid-incisal region of maxilla (U1) & The mid-point of upper central incisor tip \\
\hline Mid-incisal region of mandible (L1) & The mid-point of lower central incisor tip \\
\hline $\operatorname{Alar}(\mathrm{Al})$ & The lowest point of soft tissue ala in the coronal view \\
\hline Mid-alar (MidAl) & The mid-points of both lateral nasal soft tissue regions \\
\hline Nasion $(N)$ & The most anterior point of the frontonasal suture on the midplane \\
\hline Opisthion (Op) & The median point of the posterior border of the foramen magnum \\
\hline Optic nerve $(\mathrm{ON})$ & The mid-point where the optic nerve enters on each side \\
\hline Orbitale (Or) & The lowest point on the lower edge of the orbit \\
\hline Porion (Po) & The uppermost external point of the external auditory meatus \\
\hline Mid-porion (MidPo) & The mid-point of both porions \\
\hline Sella (S) & The landmark representing the center of sella turcica \\
\hline
\end{tabular}


structures. ${ }^{13}$ In contrast, three-dimensional (3D) imaging using computed tomography (CT) is an easy technique for quantifying the desired anatomical structures, ${ }^{13}$ with few errors caused by enlargement, distortion, and nesting. ${ }^{14,15}$ This 3D simulation has better predictability and can be used to set up a surgical plan, which is very helpful for surgery to correct asymmetric surgery. ${ }^{16}$ However, research predicting lip soft tissue changes using 3D analysis is lacking. ${ }^{5}$

Accordingly, the purpose of this study was to analyze the correlation of horizontal and sagittal planes used in $2 \mathrm{D}$ diagnosis with lip canting by using $3 \mathrm{D}$ analysis. On the basis of the results, we investigated planes that showed strong correlations with lip canting in order to determine the planes that should be prioritized for the improvement of lip canting during orthognathic surgery.

\section{MATERIALS AND METHODS}

\section{Patients and data sources}

This study was conducted according to the tenets of the Declaration of Helsinki regarding medical protocol and ethics and was approved by the Ethical Review Board of Yonsei University Dental Hospital (Institutional Review Board No. 2-2013-0004). The requirement for informed consent was waived because of the retrospective nature of the study.

From January 2010 to January 2018, we conducted a retrospective study of patients with Class 111 malocclusion who underwent CT and clinical examinations for the diagnosis of maxillofacial deformities. The exclu- sion criteria were as follows: 1) congenital deformities, including cleft lip and palate; 2) unidentified occlusal plane due to the loss of multiple teeth; 3) previous history of facial and jaw surgeries; 4) no record of frontal photographs or CT data, because of which the degree of lip canting could not be confirmed; and 5) presence of conditions causing severe ectopic positioning of the bilateral orbitale and porion (for example, hemifacial microsomia), because of which the Frankfort horizontal plane could not be reliably identified.

\section{Data collection}

\section{Acquisition of CT scans}

CT scans were acquired using a high-speed Advantage CT system (GE Medical System, Milwaukee, WI, USA). For all patients, images were scanned using the highresolution bone algorithm under the following conditions: $200 \mathrm{~mA}$; $120 \mathrm{kV}$; scanning time, 1 second; thickness, $1 \mathrm{~mm}$; and $512 \times 512$ pixels.

\section{Reorientation of CT scans}

Three-dimensional planning software (SimPlant Pro Crystal, ver. 2011; Materialize Dental Co., Leuven, Belgium) was used for analysis of the facial bones and soft tissues. 3D reconstruction of the craniofacial structures was performed using the CT scans. For reconstruction of hard tissues such as the bone and teeth, a threshold was set from 662 for the cortical bone to 3,071 for the enamel. Furthermore, for soft reconstruction, a threshold ranging from -200 to 200 was set for the creation of a
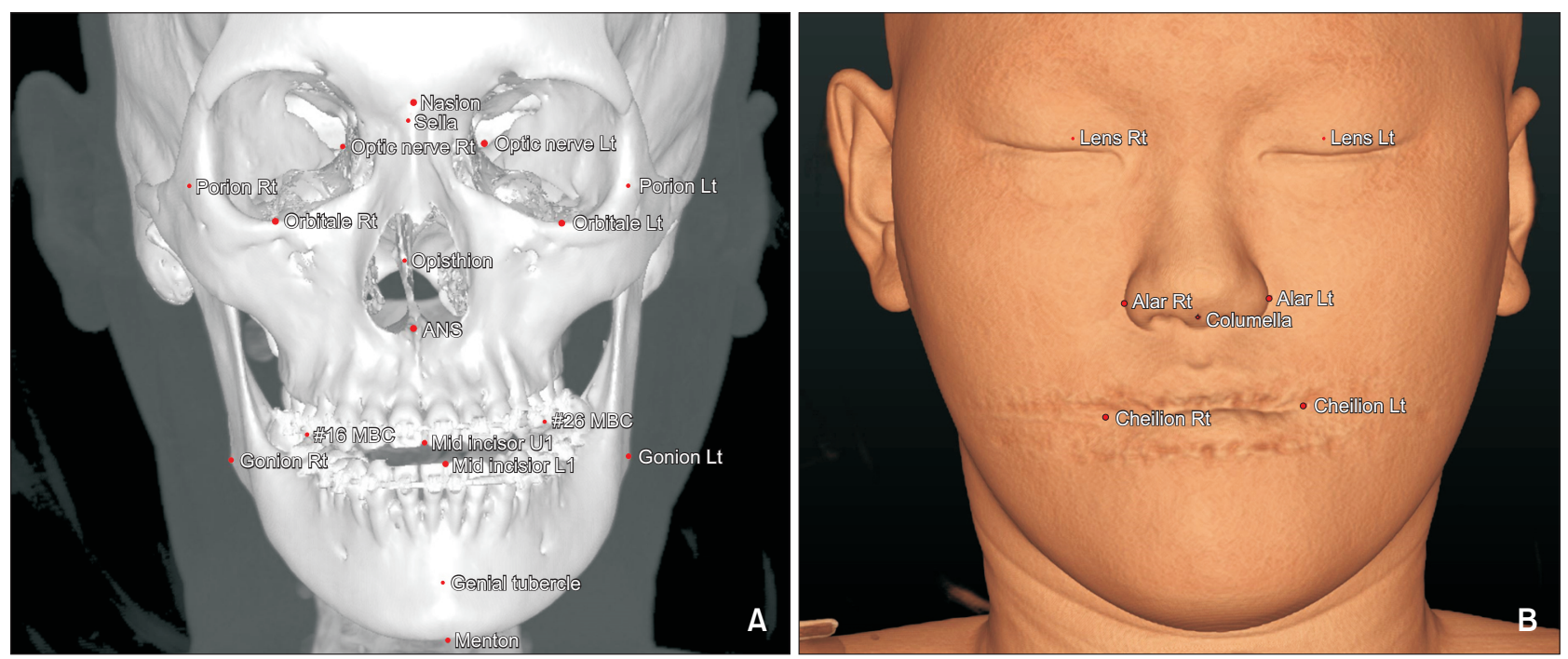

Figure 1. Craniofacial anatomical landmarks used for defining the craniofacial planes evaluated in the present study. A, Hard tissue landmarks. B, Soft tissue landmarks.

Rt, Right; Lt, left.

See Table 1 for definitions of the other landmarks. 
virtual 3D model.

\section{Setting of landmarks and planes}

\section{1) Landmarks}

A total of 23 landmarks were used in this study (Table 1, Figure 1): anterior nasal spine (ANS), cheilion (Ch), columella (Col), tragus (Tr), mid-tragus (MidTr), genial tubercle (GT), lens (L), gonion (Go), menton (Me), mesiobuccal cusp (MBC) of the maxillary first molars (\#16 and \#26), mid-cheilion (MidCh), mid-incisor of maxilla (U1), mid-incisor of mandible (L1), alar (Al), mid-alar (MidAl), nasion (N), opisthion (Op), optic nerve (ON), orbitale (Or), porion (Po), midporion (MidPo), and sella (S).

2) Reference craniofacial planes

On the basis of the landmarks, eight horizontal planes and three sagittal planes were identified. With the exception of two sagittal planes that were designed for the present study, all the identified planes have been widely used in previous studies. The two sagittal planes designed by the authors were termed the mandibular symmetry and nasal axis planes. The third sagittal plane was the mid-sagittal plane, which is the center line of the face. In addition, one coronal plane was set to measure the angle between two planes; therefore, a total of 12 planes were set. The definition of each plane is given below (Table 2).

(1) Horizontal planes associated with the cranium (Figure 2)
a) Broadbent's plane (= SN plane)
b) Optical axis plane ${ }^{17}$

(2) Horizontal and sagittal planes associated with the midface (Figure 3)
a) Frankfort horizontal plane (FH plane)
b) Camper's plane: A plane known as the Ala-tragus line ${ }^{18}$
c) His' plane
d) Occlusal plane: A plane passing through the midincisal region of the maxilla and $\mathrm{MBC}$ of the maxillary

Table 2. Definitions of the craniofacial planes evaluated in the present study

\begin{tabular}{|c|c|c|}
\hline Plane & Definition & Landmark \\
\hline \multicolumn{3}{|l|}{ Horizontal planes related with cranium } \\
\hline Broadbent's plane (SN plane) & $\begin{array}{l}\text { The plane passing from nasion to sella and perpendicular to } \\
\text { midsagittal plane (as known as S-N plane) }\end{array}$ & $\mathrm{S}, \mathrm{N}, \mathrm{MS}$ plane \\
\hline Optical axis plane & The plane constructed by 3 points; both lens and optic nerve & L (both), ON \\
\hline \multicolumn{3}{|l|}{ Horizontal planes related with midface } \\
\hline Camper's plane & The plane constructed by 3 points; both ala and mid-tragus & MidTr, Al (both) \\
\hline His' plane & $\begin{array}{l}\text { The plane passing from anterior nasal spine to opisthion } \\
\text { and perpendicular to midsagittal plane }\end{array}$ & ANS, Op, MS plane \\
\hline Frankfort horizontal plane (FH plane) & The plane constructed by 3 points; both orbitale, mid-porion & Or (both), MidPo \\
\hline Occlusal plane & $\begin{array}{l}\text { The plane passing the mid-incisor tip of maxilla and } \\
\text { mesiobuccal cusp of upper molars on both side }\end{array}$ & $\mathrm{U} 1, \# 16$ \& $26 \mathrm{MBC}$ \\
\hline \multicolumn{3}{|l|}{ Sagittal planes related with midface } \\
\hline Nasal axis plane & $\begin{array}{l}\text { A sagittal plane divides the nose into right and left halves, } \\
\text { constructed by } 3 \text { points; nasion, columella, and mid-alar }\end{array}$ & N, Col, MidAlar \\
\hline \multicolumn{3}{|l|}{ Horizontal planes related with lower face } \\
\hline Mandibular symmetry plane & $\begin{array}{l}\text { A sagittal plane divides the mandible into right and left } \\
\text { halves, constructed by } 3 \text { points; genial tubercle, menton, } \\
\text { mid-incisor tip of mandible }\end{array}$ & GT, Me, L1 \\
\hline Mandibular plane & $\begin{array}{l}\text { Drawn from the most inferior border of the ramus of the } \\
\text { mandible to menton }\end{array}$ & Go (both), Me \\
\hline Lip canting plane & $\begin{array}{l}\text { The plane passing through both side of cheilions and } \\
\text { mid-cheilion }\end{array}$ & Ch (both), MidCh \\
\hline \multicolumn{3}{|l|}{ Reference planes } \\
\hline Midsagittal plane (MS plane) & $\begin{array}{l}\text { A sagittal plane through the nasion and perpendicular to } \\
\text { Frankfort horizontal plane }\end{array}$ & N, FH plane \\
\hline N-perpendicular plane & $\begin{array}{l}\text { A coronal plane passing the nasion and perpendicular } \\
\text { to Frankfort horizontal plane and midsagittal plane }\end{array}$ & $\begin{array}{l}\text { N, FH plane, } \\
\text { MS plane }\end{array}$ \\
\hline
\end{tabular}

See Table 1 for definitions of each landmarks. 
first molars

e) Nasal axis plane: A sagittal plane crossing the nasion, mid-alar region, and columella while bisecting the nose

(3) Horizontal and sagittal planes associated with the lower face (Figure 4)

a) Mandibular plane

b) Lip canting plane

c) Mandibular symmetry plane: A sagittal plane that confirmed the symmetry of the mandible by passing through the menton, mid-incisal region of the mandible, and genial tubercle

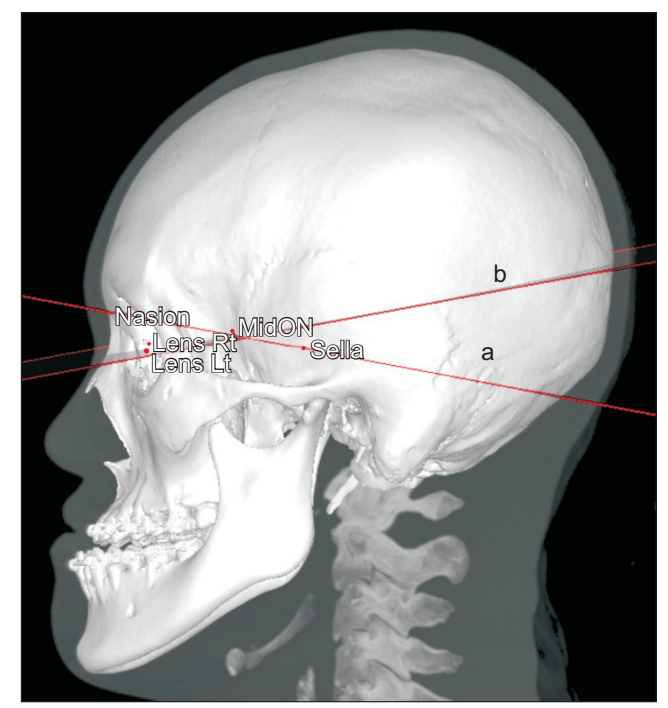

Figure 2. Horizontal planes associated with the cranium $(a$, Broadbent's plane $=$ sella-nasion plane; $b$, optical axis plane).

Rt, Right; Lt, left; MidON, mid optic nerve.
(4) Reference planes (Figure 5)

a) Midsagittal plane: The absolute sagittal reference plane that was considered the measurement standard for the nasal axis and mandibular symmetry planes

b) $\mathrm{FH}$ plane

c) N-perpendicular plane: A coronal plane for measuring the angle between planes in the frontal view

\section{Measurement of the angle between planes}

We used the FH plane and the midsagittal plane as the absolute horizontal and absolute sagittal reference planes, respectively. The angles between the horizontal planes and the absolute horizontal reference plane (FH plane) were measured on the $\mathrm{N}$-perpendicular plane. The nasal axis plane and the mandibular symmetry plane, which are sagittal planes, were measured on the $\mathrm{N}$ perpendicular planes with the absolute sagittal reference plane (midsagittal plane) (Figure 6).

The smaller of the two angles was selected, and the direction of the angle was classified into clockwise (CW) and counterclockwise (CCW) directions. An angle measured in the CW direction was assigned a positive value, while that measured in the CCW direction was assigned a negative value. This was done to facilitate the calculation of values and ensure directionality and consistency of results.

To check the intraobserver reproducibility, 2 weeks after the first measurement, the same measurer reset the 23 reference points in the same virtual 3D model, reconstructed the planes to be measured, measured the angle between two planes with the same methods used for the initial measurements, and confirmed the degree of canting.

\section{Statistical analysis}

Pearson's correlation analysis was performed to deter-

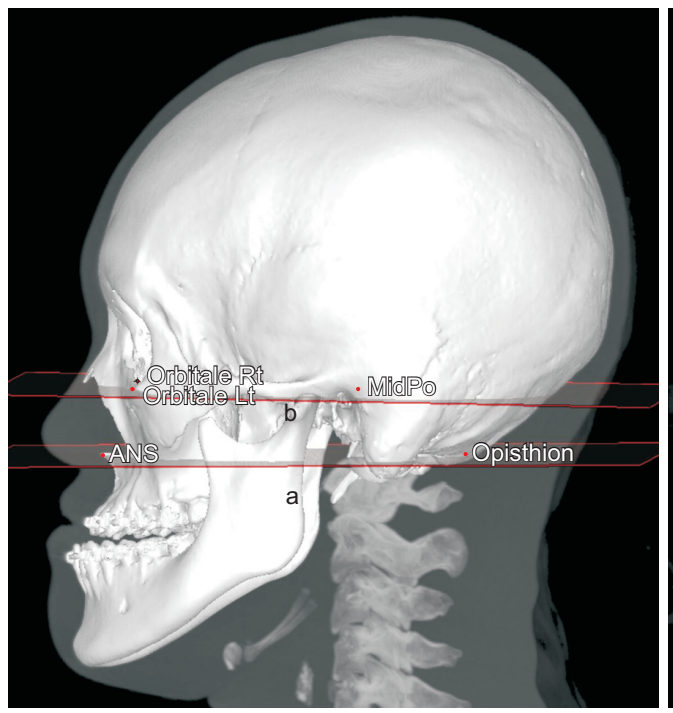

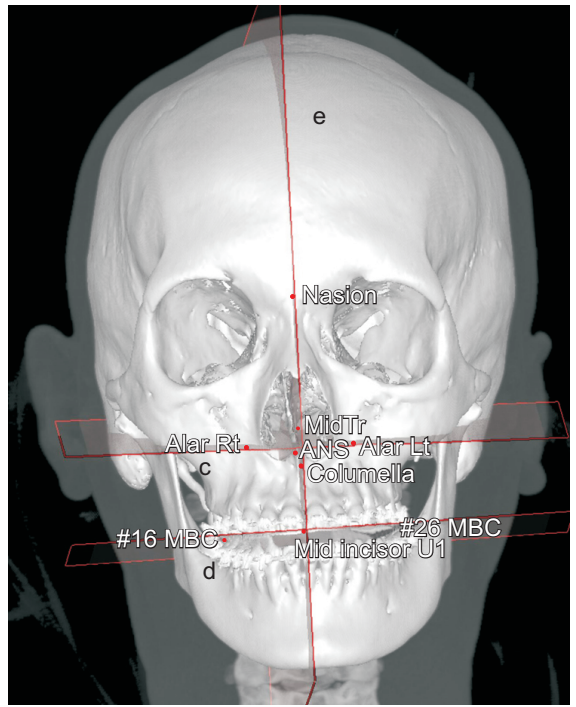

Figure 3. Horizontal and sagittal planes associated with the midface. $a$, His' plane; $b$, Frankfort horizontal plane; c, Camper's plane; d, occlusal

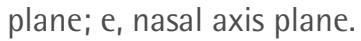
Rt, Right; Lt, left.

See Table 1 for definitions of the other landmarks. 

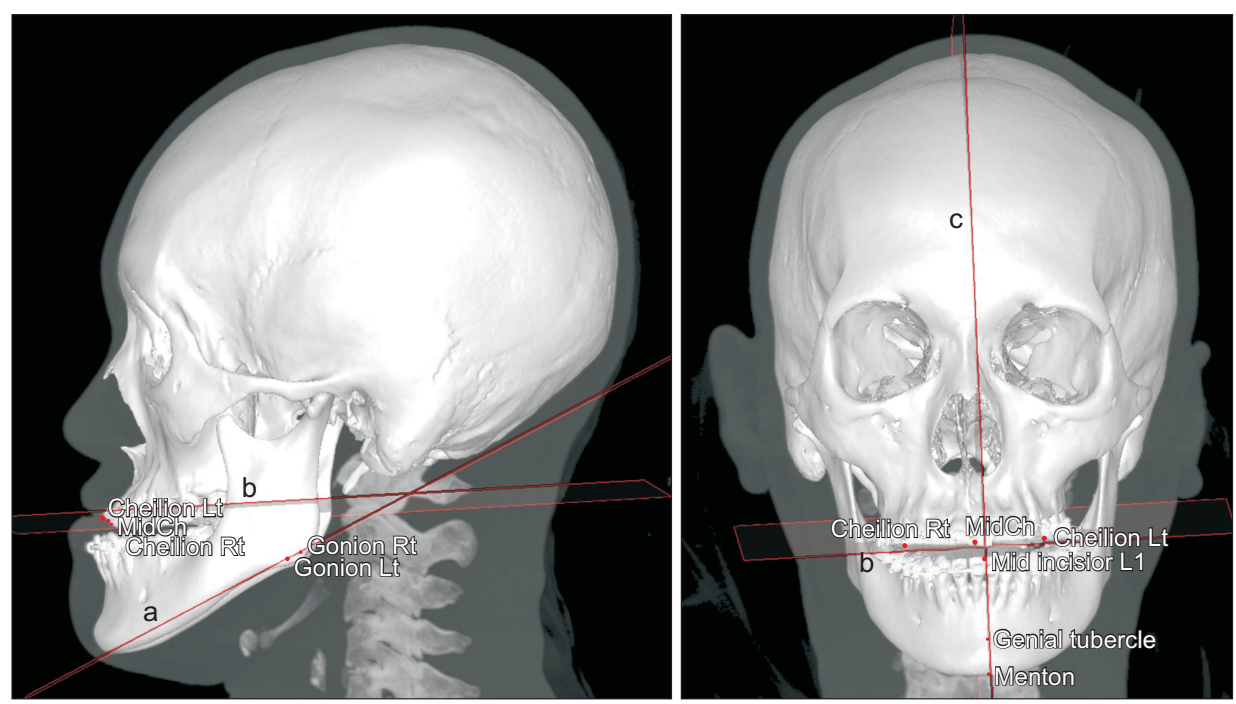

Figure 4. Horizontal and sagittal planes associated with the lower face. a, Mandibular plane; $b$, lip canting plane; $c$, mandibular symmetry plane. Rt, Right; Lt, left.

See Table 1 for definitions of the other landmarks.
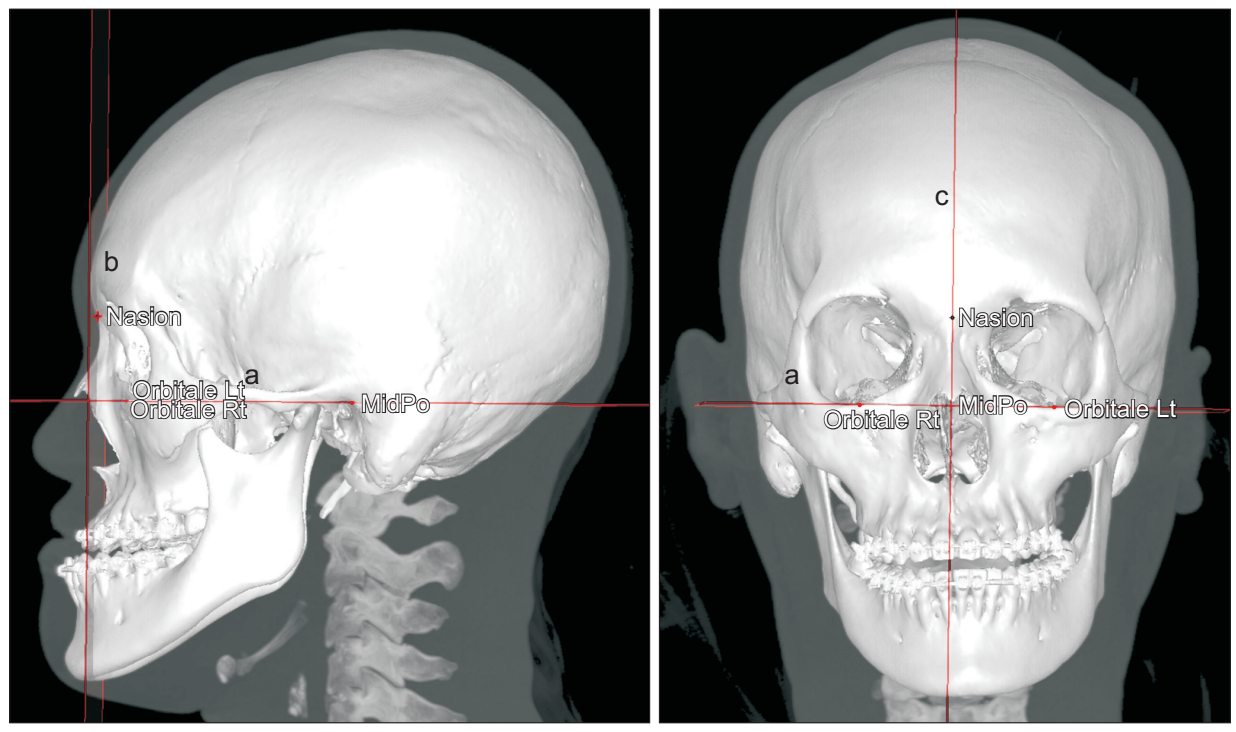

Figure 5. Reference planes used for measurement of the interplanar angle. a, Frankfort horizontal plane; $b, \mathrm{~N}$-perpendicular plane; $c_{1}$ midsagittal plane.

Rt, Right; Lt, left; MidPo, midporion.

mine the correlation between lip canting and the degree of inclination of each plane. Simple regression analysis was used to study the linear relationship between lip canting and each plane. Furthermore, depending on whether the angle between the lip canting plane and $\mathrm{FH}$ plane exceeded $3^{\circ}$, which is the criterion for clinical lip canting, we divided the patients into clinically prominent (20 patients) and not prominent (32 patients) groups and determined whether between-group differences in craniofacial plane inclinations were statistically significant. ${ }^{19}$ We performed a $t$-test for comparative analysis. Collation and calculation of all data were performed using Microsoft Excel 2007 (Microsoft, Redmond, WA, USA), and all statistical analyses were performed using the Open-Source Statistics packet software (R ver. 3.2.5; Free Software Foundation, Boston, MA, USA). A $p$-value of $<0.05$ was considered statistically significant.

\section{RESULTS}

In total, images for a total of 52 patients ( 25 men, 27 women; average age, 24 years [18-43 years]) who met the inclusion criteria were evaluated.

\section{Intraobserver reproducibility}

Pearson's correlation coefficient was determined to verify the intraobserver reproducibility. The maximum difference between the two measured values was $1.35^{\circ} / 0.89 \mathrm{~mm}$, while the mean difference was $-0.02 \% 0.15 \mathrm{~mm}$. There was no statistically significant difference between the two sets of measurements, and the initial measurements were used for our analyses. 


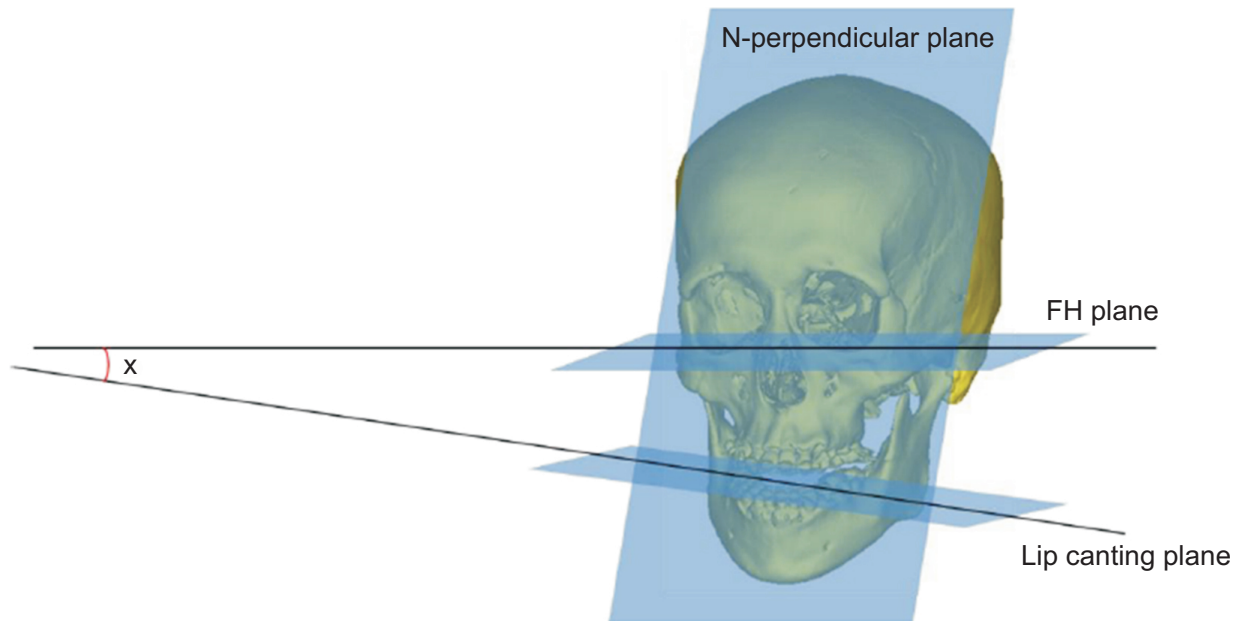

Figure 6. Schematic diagram of the method used for measuring the angle between two planes.

FH plane, Frankfort horizontal plane.

Table 3. Mean correlation coefficients and regression coefficients for various craniofacial planes evaluated in the present study

\begin{tabular}{lcclcc}
\hline \multicolumn{1}{c}{ Plane } & $\begin{array}{c}\text { Mean of the angle } \\
\text { with the reference } \\
\text { planes (degree) }\end{array}$ & $\begin{array}{c}\text { Correlation } \\
\text { coefficient (r) with } \\
\text { lip canting plane }\end{array}$ & $\begin{array}{c}\text { Strength of } \\
\text { relationship }\end{array}$ & $\begin{array}{c}\text { Regression } \\
\text { coefficient } \boldsymbol{\beta} \text { (SD) }\end{array}$ & $\boldsymbol{p}$-value \\
\hline Lip canting plane & -0.789 & 1 & & & \\
Mandibular symmetry plane & -2.185 & 0.761 & Strong & $0.397(0.048)$ & $<0.001^{* * *}$ \\
Occlusal plane & -0.251 & 0.648 & Moderate & $0.667(0.111)$ & $<0.001^{* * *}$ \\
Camper's plane & 0.027 & 0.556 & Moderate & $1.015(0.214)$ & $<0.001^{* * *}$ \\
Mandibular plane & -0.310 & 0.526 & Moderate & $0.507(0.116)$ & $<0.001^{* * *}$ \\
Broadbent's plane (S-N plane) & 0.675 & 0.438 & Weak & $0.574(0.166)$ & $0.001^{* *}$ \\
Nasal axis plane & -0.001 & 0.406 & Weak & $0.715(0.227)$ & $0.003^{* *}$ \\
His' plane & 0.470 & 0.168 & None & $0.102(0.085)$ & 0.234 \\
Optical axis plane & -0.029 & -0.012 & None & $-0.032(0.389)$ & 0.935 \\
\hline
\end{tabular}

$\mathrm{SD}$, Standard deviation.

${ }^{* *} p<0.01,{ }^{* * *} p<0.001$.

${ }^{\dagger}$ Pearson's correlation analysis.

${ }^{\ddagger}$ Simple regression analysis.

\section{Pearson's correlation analysis}

Pearson's correlation analysis revealed a strong correlation between the mandibular symmetry plane and the lip canting plane (0.761). The other planes showed moderate correlations in the following order: occlusal plane (0.648), Camper's plane (0.556), and mandibular plane (0.526). Broadbent's plane (0.438) and the nasal axis plane (0.406) showed a weak correlation with the lip canting plane, whereas His' plane (0.168) and the optical axis plane $(-0.012)$ did not show any significant correlation (Table 3).

\section{Simple regression analysis}

In simple regression analysis, the regression coefficient $(\beta)$ for each plane was determined as follows: mandibular symmetry plane, 0.397; occlusal plane, 0.667; Camp- er's plane, 1.015; mandibular plane, 0.507; Broadbent's plane, 0.574; nasal axis plane, 0.715; His' plane, 0.102; and optical axis plane, -0.032 .

Lip canting showed the strongest correlation with the planes associated with the lower face, followed by the planes associated with the midfacial region. The planes associated with the cranium showed the weakest correlation (Table 3).

\section{Craniofacial plane inclinations according to the degree of lip canting $\left(>3^{\circ}\right.$ and $\left.\leq 3^{\circ}\right)$}

The various craniofacial plane inclinations showed no statistically significant differences between the clinically prominent $\left(>3^{\circ}\right)$ and not prominent $\left(\leq 3^{\circ}\right)$ groups (Table 4$)$. 
Table 4. Comparison of various craniofacial plane inclinations between two groups stratified according to the degree of lip canting $\left(>3^{\circ}\right.$ and $\left.\leq 3^{\circ}\right)$

\begin{tabular}{|c|c|c|c|c|c|}
\hline \multirow{2}{*}{ Plane } & \multicolumn{2}{|c|}{ Lip canting to FH ( $\leq 3$ degree $)(n=32)$} & \multicolumn{2}{|c|}{ Lip canting to FH ( $>3$ degree) $(n=20)$} & \multirow{2}{*}{$p$-value } \\
\hline & Mean & SD & Mean & SD & \\
\hline Broadbent's plane (S-N plane) & 0.873 & 2.187 & 0.357 & 2.705 & 0.454 \\
\hline His' plane & 1.260 & 5.229 & -0.795 & 4.856 & 0.163 \\
\hline Optical axis plane & 0.137 & 1.273 & -0.296 & 0.831 & 0.183 \\
\hline Camper's plane & 0.088 & 1.408 & -0.072 & 2.148 & 0.770 \\
\hline Occlusal plane & 0.209 & 1.816 & -0.987 & 4.287 & 0.249 \\
\hline Mandibular symmetry plane & -1.294 & 3.558 & -3.608 & 8.493 & 0.259 \\
\hline Mandibular plane & -0.070 & 2.550 & -0.702 & 4.161 & 0.546 \\
\hline Nasal axis plane & -0.280 & 1.552 & 0.453 & 2.041 & 0.149 \\
\hline
\end{tabular}

Mann-Whitney test was performed.

FH, Frankfort horizontal plane; SD, standard deviation.

\section{DISCUSSION}

The purpose of this study was to identify the craniofacial planes showing a strong correlation with lip canting in a 3D virtual model. Our findings revealed lip canting was strongly correlated with the mandibular symmetry plane.

Lip canting occurs as a result of hard and soft tissue incongruity, including skeletal and muscular inclinations, and is known to be influenced by the occlusal plane, maxillary canting, the difference between the lengths of the two mandibular rami, and menton deviation., , 10,20,21 $^{2}$ Midsagittal plane setting is important in the research on facial asymmetry, as the asymmetry and its degree are determined in reference to these planes. In most studies, researchers have used the nasion, sella, crista galli, and ANS as landmarks to set the midsagittal plane. ${ }^{22}$ However, this sagittal plane is not reliable when there is cranial or midfacial asymmetry. ${ }^{23} \mathrm{In}$ order to overcome this problem, Ras et al. ${ }^{24}$ proposed that the plane vertically bisecting the horizontal reference plane should be used as the midsagittal plane. They also mentioned that the orbital structures may be highly reliable in patients with facial asymmetry because growth is normally completed after 8 years of age. On the basis of this concept, we set the plane perpendicular to the FH plane and passing through the nasion as the midsagittal plane in the present study.

According to Table 3, among the planes associated with the cranium, Broadbent's plane showed a significant correlation with lip canting, whereas the optical axis plane showed no correlation. The cranium is separated from the midfacial and lower facial regions; therefore, it is not directly related to the lip and surrounding tissues. The lack of a correlation between the optical axis plane and the lip canting plane could be attributed to the exclusion of patients with severe eye dystopia in the present study.

Among the planes associated with the midface, Camper's plane and the occlusal plane showed a significant correlation with lip canting, probably because of the muscles originating in the midface, such as the zygomaticus major and minor and levator labii superioris. In a previous study, maxillary canting due to asymmetric growth was found to affect lip canting because the location of these muscle attachments had changed., ${ }^{5,25}$ Recently, Freudlsperger et al. ${ }^{26}$ conducted a 3D analysis study and reported that changes in the occlusal plane after orthognathic surgery affected the improvement in lip canting. However, His' plane is defined with the ANS and opisthion, which are points associated with hard tissues. Therefore, the peri-oral muscles, which can affect lip canting, are not related to this plane. In the present study, the planes associated with the lower face showed a relatively strong correlation with the lip canting plane, with the mandibular symmetry plane showing the strongest correlation. These results are similar to those reported by Lee et al. ${ }^{12}$ and Hwang et al. ${ }^{21}$ on the basis of 2D images. In our 3D study, it was confirmed that menton deviation and dental inclination were the most influential factors with regard to lip canting.

Ferrario et al. ${ }^{27}$ reported that lip canting of $<3^{\circ}$ is generally difficult for people to perceive. Therefore, we divided our subjects into clinically prominent and not prominent groups in order to evaluate the differences between patients with clinical lip canting $\left(>3^{\circ}\right)$ and those without prominent lip canting. However, no significant difference was observed between the two groups, as opposed to our expectation. These results indicate that the clinical management of a patient with severe noticeable lip canting may not require measures additional to those used for a patient without remark- 
able lip canting. However, further research based on the results before and after treatment is necessary to substantiate this assumption.

In the case of 3D analysis using CT, it is necessary to select four points for a specific plane. Generally, bilateral anatomical landmarks are used. However, if two landmarks show a large positional difference, they cannot be used as reference points. In addition, an error may occur when defining a plane having only a single point in the midline, such as the sella. For this reason, the present study only included cases where there was no significant distance between bilateral landmarks and the sella and opisthion were located on the midsagittal line.

Some scholars have reported that skeletal asymmetry can be masked by soft tissues such as muscles and skin. ${ }^{28}$ Peck et al. ${ }^{29}$ reported that many patients with skeletal asymmetry exhibit symmetrical facial soft tissue features, and that there is a difference between skeletal asymmetry and soft tissue asymmetry. Therefore, resolution of any soft tissue asymmetry should be the basic goal of diagnosis and treatment for patients with facial asymmetry. ${ }^{12,30}$ lip canting, which is an important element of soft tissue asymmetry, should be considered in addition to the facial muscles and skeletal structure.

Several studies involving the prediction of soft tissue contours in orthognathic surgery are being conducted, and clinicians attempt to resolve lip canting by maxillary canting correction in most studies. To the best of our knowledge, the present study is the first to show that the mandibular symmetry plane is strongly correlated with the lip canting plane.

This study has some limitations. First, only preoperative CT scans were studied. Second, the sample size was small. Third, because only the preoperative condition was analyzed, no analysis was performed to determine whether the degree of lip canting reduced after surgery. Fourth, cases of severe eye and ear dystopia were excluded; therefore, patients with midfacial asymmetry were not entirely considered. Further studies should set other planes that are not affected by the positions of the orbitale and porion. Choi et al. ${ }^{31}$ measured midfacial asymmetry using the basion-perpendicular plane; such planes will also help in determining the correlations between midfacial asymmetry and lip canting.

Nevertheless, the findings of this study are clinically meaningful because, to the best of our knowledge, there is no report on the correlation between the planes used in 3D evaluation and the clinical lip canting plane. In addition, the craniofacial planes that were correlated with lip canting in the present study may change after orthognathic surgery. There is a paradigm shift from traditional 2D analysis to 3D analysis using CT. The significance of the present study lies in the fact that lip canting, which was traditionally analyzed using only $2 \mathrm{D}$ photographs, was correlated with other 3D craniofacial planes. However, further research should determine how lip canting improves with changes in these planes.

\section{CONCLUSION}

The findings of this study suggest that lip canting is strongly correlated with the mandibular symmetry plane, which includes menton deviation. This finding may have clinical implications for the treatment of patients requiring correction of lip canting. Further studies are necessary for evaluating the changes in lip canting after orthognathic surgery.

\section{CONFLICTS OF INTEREST}

No potential conflict of interest relevant to this article was reported.

\section{REFERENCES}

1. Cohen MM Jr, Richieri-Costa A, Guion-Almeida ML, Saavedra D. Hypertelorism: interorbital growth, measurements, and pathogenetic considerations. Int J Oral Maxillofac Surg 1995;24:387-95.

2. Huang CS, Liu XQ, Chen YR. Facial asymmetry index in normal young adults. Orthod Craniofac Res 2013;16:97-104.

3. Kim SJ, Choi JY, Baek SH. Evaluation of canting correction of the maxillary transverse occlusal plane and change of the lip canting in Class 111 two-jaw orthognathic surgery. Angle Orthod 2012;82:10927.

4. Choi JY, Choi JP, Lee YK, Baek SH. Simultaneous correction of hard- and soft-tissue facial asymmetry: combination of orthognathic surgery and face lift using a resorbable fixation device. J Craniofac Surg 2010;21:363-70.

5. Kim YH, Jeon J, Rhee JT, Hong J. Change of lip cant after bimaxillary orthognathic surgery. J Oral Maxillofac Surg 2010;68:1106-11.

6. Padwa BL, Kaiser MO, Kaban LB. Occlusal cant in the frontal plane as a reflection of facial asymmetry. J Oral Maxillofac Surg 1997;55:811-6; discussion 817.

7. Chu EA, Farrag TY, lshii LE, Byrne PJ. Threshold of visual perception of facial asymmetry in a facial paralysis model. Arch Facial Plast Surg 2011;13:14-9.

8. Sarver DM, Ackerman MB. Dynamic smile visualization and quantification: part 1. Evolution of the concept and dynamic records for smile capture. Am J Orthod Dentofacial Orthop 2003;124:4-12.

9. Song WC, Koh KS, Kim SH, Hu KS, Kim HJ, Park JC, et al. Horizontal angular asymmetry of the face in 
korean young adults with reference to the eye and mouth. J Oral Maxillofac Surg 2007;65:2164-8.

10. Gazit-Rappaport T, Weinreb M, Gazit E. Quantitative evaluation of lip symmetry in functional asymmetry. Eur J Orthod 2003;25:443-50.

11. Trpkova B, Major P, Nebbe B, Prasad N. Craniofacial asymmetry and temporomandibular joint internal derangement in female adolescents: a posteroanterior cephalometric study. Angle Orthod 2000;70:81-8.

12. Lee MS, Chung DH, Lee JW, Cha KS. Assessing soft-tissue characteristics of facial asymmetry with photographs. Am J Orthod Dentofacial Orthop 2010;138:23-31.

13. Ludlow JB, Gubler M, Cevidanes L, Mol A. Precision of cephalometric landmark identification: conebeam computed tomography vs conventional cephalometric views. Am J Orthod Dentofacial Orthop 2009;136:312.e1-10; discussion 312-3.

14. Lonic D, Sundoro A, Lin HH, Lin PJ, Lo LJ. Selection of a horizontal reference plane in 3D evaluation: ldentifying facial asymmetry and occlusal cant in orthognathic surgery planning. Sci Rep 2017;7:2157.

15. Trpkova B, Prasad NG, Lam EW, Raboud D, Glover KE, Major PW. Assessment of facial asymmetries from posteroanterior cephalograms: validity of reference lines. Am J Orthod Dentofacial Orthop 2003;123:512-20.

16. De Riu G, Meloni SM, Baj A, Corda A, Soma D, Tullio A. Computer-assisted orthognathic surgery for correction of facial asymmetry: results of a randomised controlled clinical trial. Br J Oral Maxillofac Surg 2014;52:251-7.

17. Kang YH, Kim BC, Park KR, Yon JY, Kim HJ, Tak HJ, et al. Visual pathway-related horizontal reference plane for three-dimensional craniofacial analysis. Orthod Craniofac Res 2012;15:245-54.

18. Lahori M, Nagrath R, Malik N. A cephalometric study on the relationship between the occlusal plane, ala-tragus and Camper's lines in subjects with Angle's Class 1, Class 11 and Class 111 occlusion. J Indian Prosthodont Soc 2013;13:494-8.

19. Ferrario VF, Sforza C, Poggio CE, Tartaglia G. Distance from symmetry: a three-dimensional evaluation of facial asymmetry. J Oral Maxillofac Surg 1994;52:1126-32.

20. Cho JH, Kim EJ, Kim BC, Cho KH, Lee KH, Hwang HS. Correlations of frontal lip-line canting with cra- niofacial morphology and muscular activity. Am J Orthod Dentofacial Orthop 2007;132:278.e7-14.

21. Hwang HS, Youn IS, Lee KH, Lim HJ. Classification of facial asymmetry by cluster analysis. Am J Orthod Dentofacial Orthop 2007;132:279.e1-6.

22. Tuncer BB, Ataç MS, Yüksel S. A case report comparing 3-D evaluation in the diagnosis and treatment planning of hemimandibular hyperplasia with conventional radiography. J Craniomaxillofac Surg 2009;37:312-9.

23. Terajima M, Nakasima A, Aoki Y, Goto TK, Tokumori K, Mori N, et al. A 3-dimensional method for analyzing the morphology of patients with maxillofacial deformities. Am J Orthod Dentofacial Orthop 2009;136:857-67.

24. Ras F, Habets LL, van Ginkel FC, Prahl-Andersen B. Method for quantifying facial asymmetry in three dimensions using stereophotogrammetry. Angle Orthod 1995;65:233-9.

25. Marinetti CJ. The lower muscular balance of the face used to lift labial commissures. Plast Reconstr Surg 1999;104:1153-62; discussion 1163-4.

26. Freudlsperger C, Rückschloß T, Ristow O, Bodem J, Kargus S, Seeberger R, et al. Effect of occlusal plane correction on lip cant in two-jaw orthognathic surgery - a three-dimensional analysis. J Craniomaxillofac Surg 2017;45:1026-30.

27. Ferrario VF, Sforza C, Miani A, Tartaglia G. Craniofacial morphometry by photographic evaluations. Am J Orthod Dentofacial Orthop 1993;103:327-37.

28. Yogosawa F. Predicting soft tissue profile changes concurrent with orthodontic treatment. Angle Orthod 1990;60:199-206.

29. Peck S, Peck L, Kataja M. Skeletal asymmetry in esthetically pleasing faces. Angle Orthod 1991;61:438.

30. Van Hemelen G, Van Genechten M, Renier L, Desmedt M, Verbruggen E, Nadjmi N. Three-dimensional virtual planning in orthognathic surgery enhances the accuracy of soft tissue prediction. J Craniomaxillofac Surg 2015;43:918-25.

31. Choi YK, Park SB, Kim Yl, Son WS. Three-dimensional evaluation of midfacial asymmetry in patients with nonsyndromic unilateral cleft lip and palate by cone-beam computed tomography. Korean J Orthod 2013;43:113-9. 